\title{
A study on the Source of Competitive Advantage in Uncertainty Environment: From the View of Dynamic Capability and Path Dependent
}

\author{
Xiyuan WANG ${ }^{1,2}$ \\ Donghua university \\ ${ }^{1}$ Tongji University Shanghai Institute of Design and \\ Innovation, Shanghai, 200051, China \\ ${ }^{2}$ Business School \\ Instituto Universitário de Lisboa (ISCTE-IUL) \\ Lisbon, Portugal \\ shbjy001@163.com
}

\author{
Hao SHI \\ Business School \\ Instituto Universitário de Lisboa (ISCTE-IUL) \\ Lisbon, Portugal
}

\author{
Qingyang ZHANG \\ Innovation and Management \\ Donghua university \\ Shanghai, China
}

\begin{abstract}
This study is going to reveal the real source of enterprise competitive advantage under moderate changed environments and high-velocity environments. Based on the literature review, the factor of environmental dynamism is drawn into the study structure, and a system dynamics analysis was made on the source of competitive advantage in an uncertain environment. The system dynamics loop structure of competitive advantages under moderate changed and high-velocity environments are founded. To reveal the real source of competitive advantage under environments of those two mentioned above, which contributes to the improvement of strategy management research in some sense.
\end{abstract}

Keywords-Competitive Advantage; Dynamic Capabilities; Path-dependent; System Dynamics

\section{INTRODUCTION}

In recent years, the uncertainty of the enterprise development environment is increasing. The limitations of the theories that focus on the resources and hold that the competitive advantage comes from the endogenous of the enterprises are increasingly apparent, like Resources Basic View and Core Competence theory. Barton(1992)put forward the concept "core rigidities" and it directly reveals the short board of the path dependence and core competence in the changing environment [1]. Teece (1994) proposed the dynamic capabilities theory, which maintains the enterprise competitive advantage and used to break existing routines and establish new routines [2]. This theory places the enterprise into the dynamic developing competitive environment and emphasizes the mechanism that the company regulates the resource allocation according to changes in the external environment, in order to break the core rigidity and maintain the core competitive advantages. While, current research on the process of how does dynamic capabilities influence the enterprises to break existing routines and establish new routines, and to maintain the competitive advantage is not very in-depth study. In this study, two factors were introduced to observe and open the black box of the source of competitive advantage. The method of system dynamics is used in this research.

\section{Current Research}

\section{A. Path Dependence and Competitive Advantage}

Path dependence is widely used in the research of technological change and institutional change in the economics. But in the organization research, the path dependence was used to describe the historical matters of an enterprise and it was a development path that cannot avoid. The development of enterprise is not only depends on the real benefits, but also affected by the initial conditions of the development path.

Arthur(1989)point out that path dependence always started in the occasional historical small probability event [3]. Corresponding to the research in organization, this kind of historical small probability event represent a kind of revelation case that good to the enterprise development and be used by the enterprise in the changing environment. After be selected, it will be quickly routinized by the enterprise.

Once an organization enters a path, the process will be enhanced since the system externality, organizational learning effects, and historical subjectivism (enterprise routines) derived from these questions in history (North, 1997) [4], and it means that the path will enter the self-strengthening mechanism after be selected. Qiu (2008) proposed that the self-strengthening mechanism is the stage of forming dominant logic through the routine, and the stage of learning through imitation and copy [5]. This mechanism is started from the historic small 
probability events and following the path of organizational routines. And it also explains why enterprise routines have the path-dependent characteristics.

On this basis, self-strengthening mechanism will promote the path dependence into the "locking" state, making the path dependence becomes "invalid innovation" and has a "track tenacious" (Huang and Wang, 2006) [6]. At this moment, organizational behavior is in accordance with the "locking" routine automatically. It is going to break the "locking" initiatively, only when the organization feel the pressure from the changes in the external environment. At the beginning, path dependence has an increasing return effect, and it will promote the enterprise input-output into a lock that in line with "Pareto Optimality". In the research of organization, the efficient of "locking" is the source of core capability of enterprise.

However, the increasing return effect of "locking" will be eroded gradually by the changing environment. It becomes more and more ineffective and no longer suit to the new development environment. Finally, invalid "locking" becomes the source of core rigidity. Organizational flexibility is the important factor to break the inefficient "locking" of the enterprise. Dynamic ability is the concrete manifestation to keep the Organizational flexibility.

\section{B. Dynamic Capability and Competitive Advantage}

Teece (1994) defined the dynamic capability as the process that contributes to the organization in the timely adjustment, integration and reconstruction of internal resources and the ability, in a constantly changing competitive environment [2]. And then put forward the analysis framework of the dynamic capability and it named 3P model (Teece, 1997) that dynamic capabilities embedded in the enterprise organization process (Process) which determined by the enterprise resource potential (Position) and evolution path (Path) [7]. Further, Teece (2007) holds that dynamic capabilities should include sensing, seizing, and reconfiguration of the ability to integrate, protect, and reorganize enterprise resources to maintain competitiveness dimension [8]

Sensing ability is mainly the ability of enterprises to identify existing threats and seek opportunities for development. In order to break the core rigid restrictions and to maintain the competitive advantage, the enterprises have to get the complete information, perceive whether the degree of their own conditions can suit the development of the environment, and identify the core rigid threat and the fleeting market opportunities. That mainly reflected in that the enterprise can sense and judge the current operation at any time, can judge that whether the output of the existing "locking" can meet the needs of the market and customers. Meanwhile it also reflected in sensing the external changes such as the changes in market, policy, economic environment, social networks. Then recognize the potential threats and opportunities during the development of the enterprises in time.

Li Dayuan (2012) argues that when threats and opportunities are identified, enterprise managers need to make rapid decision of change, and the faster to make the decision, the higher possibility that companies can seize the opportunity or avoid the threat to regain the competitive advantage [9]. On the basis of existing enterprise resource and their configuration, managers find a solution quickly to deal with the threat. That process brings an opportunity to change the path dependence, and the solution will become a "Historical small probability event" to affect the new path dependence.

When managers decide to break the path dependence, companies need to combine their own resource potential and decision-making plan and format new operating practices and capabilities through the establishment, integration, reconstruction and release of the resources (Eisenhardt, 2000) [10]. That reflects the destructive creation features of dynamic ability, seeking Schumpeter rent with innovative behavior, and promoting the formation of new paths to maintain the core competitive advantage.

This "destruction" and "creation" require companies to take higher opportunity costs and huge risks. That explains why many companies choose to maintaining the status strategy, when they face the dramatic changes in the environment while their development path cannot adapt to the changes.

\section{SYSTEM DYNAMICS ANALYSIS OF THE SOURCE OF}

\section{COMPETITIVE ADVANTAGE IN AN UNCERTAINTY ENVIRONMENT}

The change of the enterprise strategic path is the result of the combination effect from external shock and internal pressure (Woerdman, 2004) [11]. When the old routine of the enterprise no longer suit to the environment and the path dependence feature obstructs the sustainable competitive advantage seriously, the dynamic capability will break this ineffective path dependence and reconstruct the new strategic path. Here we consider the acquisition of competitive advantage in two uncertain environments and that will help us to have a clear understanding of the source of competitive advantage.

\section{A. Systematic Dynamic Analysis of Competitive Advantage in moderate changing environment}

For a moderate changing environment, changes are ongoing, but generally changed along a linear trajectory, in which the industrial structure is relatively stable, the market boundaries are relatively clear, and the basic behavior of the enterprise is following the general market rules of supply and demand, and the evolution of the enterprise is following the linear trajectory of the slow changing commercial ecosystem. In this environment, once the enterprise's path dependence formed, it will promote enterprises to survive and maintain a certain competitive advantage. Even enter the inertial consciousness stage and the marginal output of enterprises gradually reduced, but the output of path dependence "locking" is still effective. So companies will not rush to spend a huge investment to break the old path-dependence. Many scholars suggest that in a moderate changing environment, decision makers can use existing knowledge and experience to plan and organize business behavior in a fixed model (Burns,1961) [12]. And develop an efficient enterprise process following the predictable and relatively stable steps (Helfat, 2009) [13]. Thus, in a moderate changing environment, the source of competitive advantage is a simple system dynamics model with a selfreinforced forward loop, as shown in Fig. 1. 


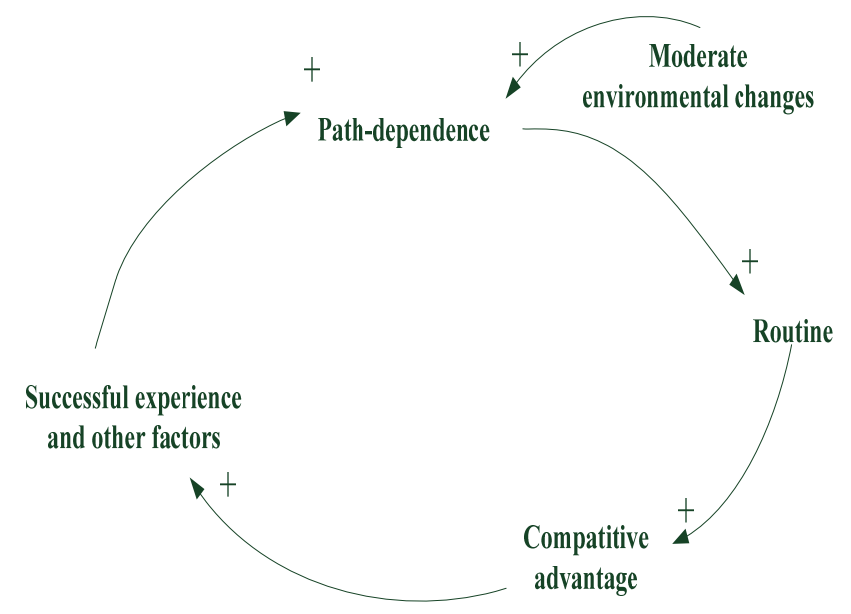

Fig. 1. Self - Reinforced Loop of Competitive Advantage System in Moderate Changing Environment

From a system dynamics point of view, there is not any system can grow or evolve indefinitely, and each system should have a suppression loop. One day, the development of the system will touch the suppression factor, so that the development of the system slows down or even stagnate (Cai, 2011) [14]. Within moderate changing environment, intraindustry market resources are relatively rich, and the resource growth rate is also at a high level (otherwise the competition around the resources will bring high-speed changes into the development environment). However, the competitive advantage let the company grow fast, which will squeeze the competitors living space and stimulate competitors to choose a new alternative technology or products. So, the inhibitory factor for the enterprise competitive advantage is mainly from the innovation and transformation of the competitors. For the enterprise itself, the limited nature of the enterprise resource potential cannot create unlimited returns for the enterprise, and the marginal return of the routines gradually decline after they reach the "Pareto equilibrium" (or even not). Therefore, under the moderate changing environment, the inhibitory factors of the enterprise competitive advantage mainly come from the resource potential of the enterprise itself and the competitors. And that constitutes the suppression loop of the competitive advantage system, as shown in Fig. 2.

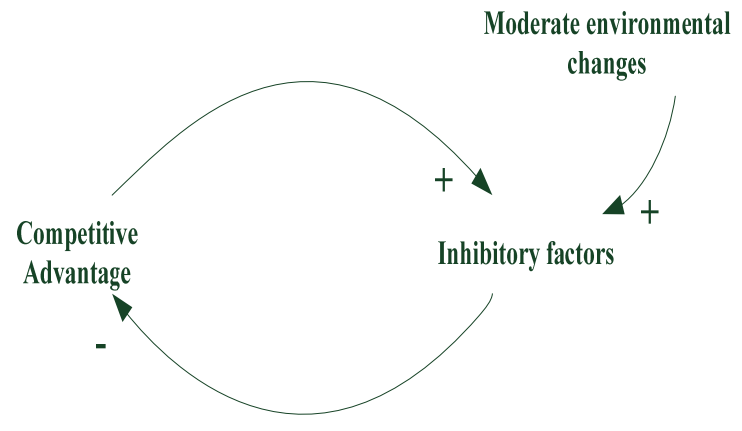

Fig. 2. The competitive advantage of the suppression loop system in the moderate changing environment.
Therefore, we propose that: in a moderate changing environment, the path dependence can promote the maintenance of competitive advantage. And even if the competitive advantage is affected by inhibitory factors, the strategic path of the enterprise will not be a fundamental change. Meanwhile, the relation between dynamic capability and competitive advantage shows a weak correlation.

\section{B. Systematic Dynamic Analysis of Competitive Advantage in High-speed changing environment}

In the high-speed environment, the market boundaries become very vague, and the market participants are no longer determined. The business operation not only impacted by the market supply and demand, but also may relate to government administrative intervention, policy environment and other factors. The change is no longer linear and predictable which means that the business ecosystem is extremely unstable. In this case, the long-term maintenance of competitive advantage becomes less likely. That because the competitive advantage depends on the effectiveness of the path dependence. The nonlinearity and uncertainty of the change will quickly erode the path dependence of the increasing returns, and the "locking" will soon enter the "core rigid". Any competitive advantage will continue to be threatened. Therefore, in the high-speed changing environment, to maintain long-term competitive advantage is actually the process to achieve a series of shortterm advantage continually (Daveni, 2010) [15]. In the highspeed changing environment, we observed that some enterprises always have a competitive advantage. That actually is a dynamic equilibrium evolution process about the passive regression and initiative regain of the competitive advantage.

In the high-speed changing environment, the enterprise dynamic capacity will be in a very active state. That because the company with strong dynamic capabilities can continue to perceive the threat from the inefficient path dependence. So companies will continually reset their own resources based on the strategic path of decision-making. Then the company can obtain the new value of resources, and optimize the allocation of resources, and achieve enterprise's short-term growth and a short competitive advantage during a formation of a pathdependent. But the drastic environment changing will soon increase the operating costs of enterprises, and decline the output, and erosion the effectiveness of path dependence. So the enterprise will immediately start the dynamic capabilities as soon as it enter the inert thinking stage, and re-positioning the environment needs and re-configure the resources. So the "long-term" maintenance of the competitive advantage of the enterprise is a dynamic equilibrium process

In this case, the enterprise's development path is in a state of instability. The companies are always in the process of comparison, selection and abandonment. While the company that cannot maintain organizational flexibility and the sensing capability will follow a path and form a fixed routine. And when the enterprise enters the inertia stage and inert thinking stage, it will threaten the competitive advantage of the enterprise.

Therefore, there are two loop of the competitive advantage. The enhanced loop of the system is: Competitive Advantage $\ldots+>$ Dynamic Capability __+ $>$ Knowledge Inventory - 
Sensing Capability —_ $+>$ Resource Reset Capability $+>$ Creating New Value__ $+>$ Resource Stock and Optimized Configuration $-+>$ Competitive Advantage. And the suppression loop of the system is: Competitive
Advantage —— $>$ Successful Experience and Other Factors $-+>$ Path Dependence —- $>$ Routine —- $>$ Competitive Advantage. As shown in Fig. 3.

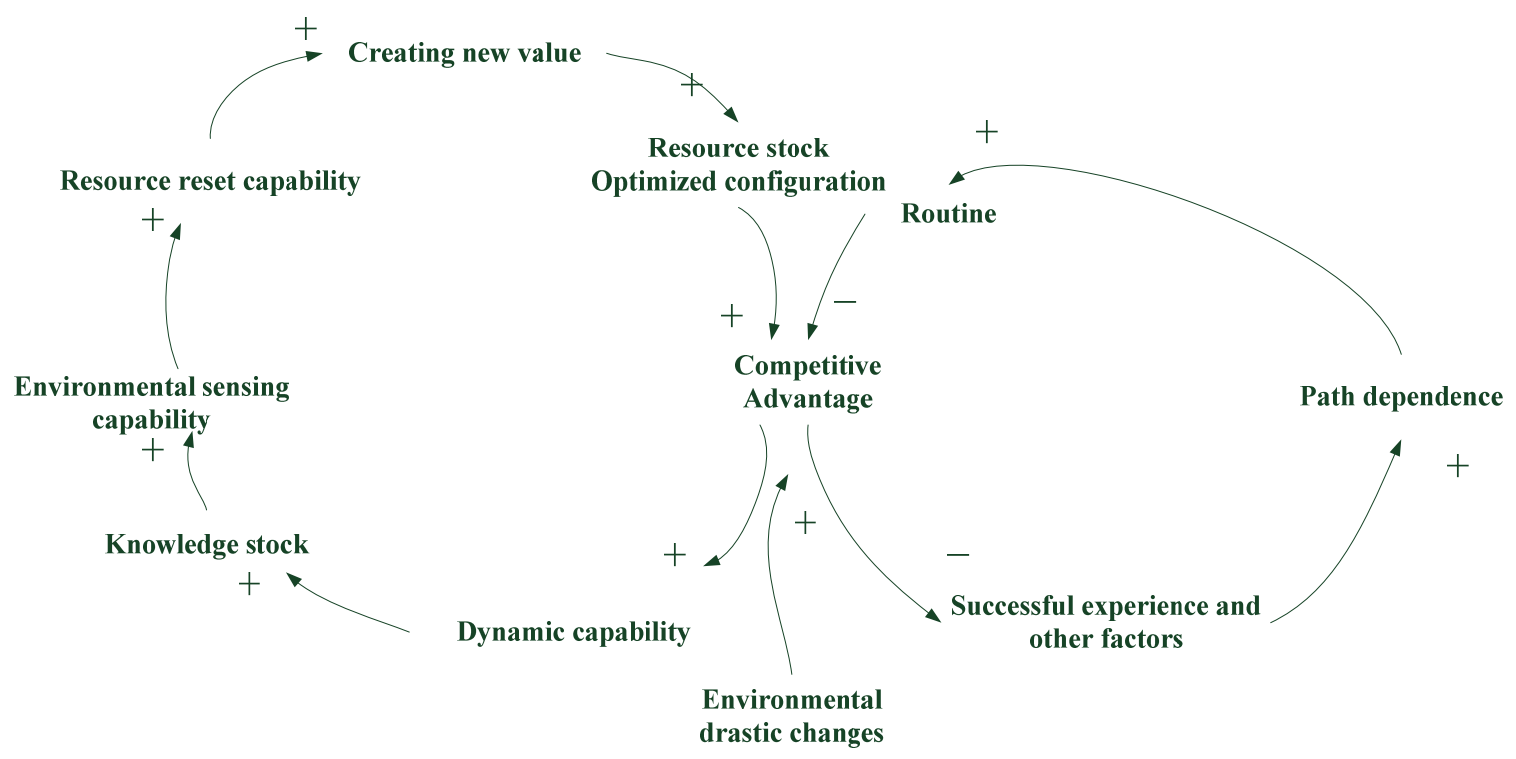

Fig. 3. The dynamic model of competitive advantage in high-speed changing environment

Therefore, we propose that, in the high-speed changing environment, the power of the competitive advantage of the self-enhanced loop is given by the dynamic capability. While the suppression loop mainly arises from the path dependence of the enterprise.

\section{CONCLUSION}

To maintain the competitive advantage is the process of enterprise dynamic capability to break the old routine and establish new routine.

Firstly, this article starts from the study of the basic business routine, setting up the system structure of the formation of enterprise routine, and uncover the formation mechanism of enterprise routine.

Secondly, analyze the decision process of path evolution. Discusses the motivation and background of the enterprise to break the path dependence, and then lead to the decisionmaking time of the dynamic capability.

Thirdly, based on the evolution process of enterprise strategic path, this paper studies the concrete function and mechanism of dynamic ability in each stage of path evolution.

Finally, this paper introduces the uncertainty of environmental factors, establishing the system dynamics of enterprise competitive advantage in moderate changing environment and high-speed changing environment. And this paper point out that in the moderate changing environment, the path dependence promote the sustainable competitive advantage of the enterprise. While in the high-speed changing environment, dynamic capacity is the long-term source of sustainable competitive advantage.

However, this article did not give an answer about how to use the system dynamics method to establish the competitive advantage, and the mathematical relationship of dynamic ability and path dependence and verify that. That can be the direction of future research.

\section{REFERENCES}

[1] Leonard Barton D. Core capabilities and core rigidities: A paradox in managing new product development $[\mathrm{J}]$. Strategic management journal, 1992, 13(S1): 111-25.

[2] Teece D, Pisano G. The dynamic capabilities of firms: an introduction [J]. Industrial and corporate change, 1994, 3(3): 537-56.

[3] Arthur W B. Competing technologies, increasing returns, and lock-in by historical events [J]. The economic journal, 1989, 99(394): 116-31.

[4] North D C. The contribution of the new institutional economics to an understanding of the transition problem [M]. UNU World Institute for Development Economics Research, 1997.

[5] Qiu Guodong. From the perspective of system dynamics, a research on the dynamic capability of enterprises [J]. Research on Financial and Economic Issues, 2008, 04): 98-104.

[6] Huang Wei, Wang Zhaofeng, Yang Anhua. Based on the path dependence theory, a study of definition standard of the Enterprise core competitiveness[J]. East China Economic Management, 2006, 06): 81-5.

[7] Teece D J, Pisano G, Shuen A. Dynamic capabilities and strategic management [J]. Strategic management journal, 1997, 18(7): 509-33.

[8] Teece D J. Explicating dynamic capabilities: the nature and microfoundations of (sustainable) enterprise performance $[\mathrm{J}]$. Strategic management journal, 2007, 28(13): 1319-50. 
[9] Li D-Y, Liu J. Dynamic capabilities, environmental dynamism, and competitive advantage: Evidence from China [J]. Journal of Business Research, 2012.

[10] Eisenhardt K M, Martin J A. Dynamic capabilities: what are they? [J]. Strategic management journal, 2000, 21(10-11): 1105-21.

[11] Woerdman E. Path dependent climate policy: the history and future of emissions trading in Europe [J]. European Environment, 2004, 14(5): 261-75.
[12] Burns T E, Stalker G M. The management of innovation [J]. University of Illinois at Urbana-Champaign's Academy for Entrepreneurial Leadership Historical Research Reference in Entrepreneurship, 1961.

[13] Helfat C, Peteraf M. Understanding dynamic capabilities: progress along a developmental path [J]. Strategic organization, 2009, 7(1): 91.

[14] Cai Shutang. Based on the system dynamics theory, a research on the supporting strength for the sustainable development of enterprise [J]. Science and Technology Management Research, 2011, 10: 103-6-11.

[15] Daveni R A, Dagnino G B, Smith K G. The age of temporary advantage [J]. Strategic Management Journal, 2010, 31(13): 1371-85. 